DOI: https://doi.org/10.24297/ijmit.v14i0.8429

\title{
The Moderating Effect of Organizational Characteristics on The Relationship Between Information Technology Integration and Performance: Empirical Evidence from Selected Public Hospitals in Kenya
}

\author{
${ }^{1}$ lloka Kenneth Malongo, ${ }^{2}$ Stephen Muathe, ${ }^{3}$ Stephen Titus Waithaka \\ School of Business, Kenyatta University P.O. Box 43844-00100. Nairobi, Kenya \\ 1kiloka2000@gmail.com, 2muathesm@yahoo.com, 33waithast@gmail.com
}

\begin{abstract}
With the continuing digital revolution steered by the Internet, organizations are moving towards information technology integration to improve their performance. Regrettably, these developments have in no way been all-inclusive. The health gap between public institutions in first, second, and third world nations has broadened. Public organizations in second and third world nations are characterized by poor performance. This study sought to establish the moderating effect of organizational characteristics on the relationship between information technology and the performance of public hospitals in Kenya. The study used the Technology Organization Environment (TOE) theory. The study was guided by explanatory and cross-sectional research design. The target population was 98 public hospitals in Kenya. Multi-stage sampling technique was used to select a sample size of 294 respondents. Primary data was collected using semi-structured questionnaires. For data analysis, descriptive statistics and multiple regression analyses were used. The study results established that organizational characteristics moderated the relationship between information technology integration and the performance of public hospitals in Kenya. Therefore, the study concluded that organizational characteristics play a major role in an organization's adoption and utilization of information technology integration. The study recommends technologies should be customized to fit the type of organizational characteristics for better performance.
\end{abstract}

Keywords: Information Technology In Kenya, Organizational Characteristics, Public Hospitals, Information Technology Integration

\section{Introduction}

Hospitals are essential in ensuring the better well-being of the citizens as well as that of nations [28]. Not only do underperforming hospitals hamper social and economic development, but they can also have an unfavorable effect on the economic prospects of countries [28]. The use of information technology such as automation of medical records, electronic consultation bookings, the use of the Internet for communication purposes and the use of magnetic cards in hospitals has been embraced by developed and developing countries. Despite the widespread use of Information Technology (IT), 90 percent of hospitals in the United States of America (USA) still use pagers and overpay by 45 percent to maintain legacy paging services [3].

In an effort to enhance the nature of care, health institutions regularly focus on a single process with solitary or interventional solutions. Though important, this strategy is iterative; an institution may ignore the actual opportunity to lay the basis for improved healthcare. Information technology integration links the key foundations of innovation in manpower, software, hardware, data management, information, feedback, and policies and procedures to improve quality of service delivery [10]. Stand-alone medical systems have had tendencies to encounter errors, communication breakdowns, and inefficiencies. It is evident that information technology integration of medical equipment and computer systems are required to drive health institutions to a better level of healthcare service delivery [2].

In the Kenyan context, the Government has acknowledged the importance of public institutions and has underlined healthcare as one of the elements of the social pillar of Kenya's Vision 2030 blueprint [21]. 
Consequently, healthcare has been devolved to get closer to the people in the wake of the 2010 constitution. Both national and county governments are expected to provide the highest affordable standard of inclusive and affordable healthcare for the people. It is anticipated that improved healthcare will play a significant role in spurring economic growth, alleviating poverty, and fulfilling social objectives [21]. In addition, the operationalization of the Health Act 2017 has clearly defined how healthcare service provision shall be undertaken, with the national government playing more of a policy and regulatory role with the provision of patient care service delivery limited to national referral hospitals [22]. However, the performance of public hospitals has been crippling due to the increasing demand and need for healthcare, among other challenges [17].

With the continuing digital revolution ushered by the Internet, institutions are moving towards information technology integration to lower their operational costs, boost productivity and quality, and react quickly to the needs of their customers and other partner organizations [12]. The framework for Technology-OrganizationEnvironment (TOE) conceives that information technology integration plays a key role in continuing to support organizational processes and thus the magnitude of IT use hinges on the information technology integration of organizations, which in turn successfully transforms prevalent technologies into capabilities [15].

According to [1], health infrastructure, education, incomes, and opportunities around the globe have improved steadily due to information technology integration. Economic and social developments have led to lower mortality and increased life expectancy. Regrettably, these developments have in no way been all-inclusive. The health gap between first, second, and third world nations has broadened, perhaps because of imbalance in the assimilation of innovations and additionally unequal circulation of new and re-emerging medical issues [1].

Reference [18] established that information technology integration, considering dimensions of human information technology integration (ITI), organizational ITI, and physical ITI explain both financial and nonfinancial performance of organizations. Their study was, however, carried out in financial institutions which are profit-oriented. Reference [24] and [19] affirm that Institutional and Organizational Assessment (IOA) Model constructs of effectiveness, relevance, efficiency, and financial viability are the organizational performance indictors recommended for non-profit making organizations such as public hospitals.

The value proposition of information technology for organizations is complex [6]. Numerous studies have investigated the impact of information technology on organizational performance. In so doing, they have identified some factors related to organizations' characteristics, for instance, size and age, considered to be moderators. According to the study, an organization's size and age are pointers of past performance. Further, reference [20], supports the argument that organizational characteristics can influence performance. For instance, bigger organizations, unlike small ones, tend to operate with a large pool of resources.

Identifying the organizations' characteristics that determine the effect of ITI on organizational performance is a management's fundamental responsibility. Nevertheless, the important viewpoint is not generally the asset base. Rather, it is the resources that are bundled together to form distinct capacity for an organization such as ITI [15]; [6]). The organization's life expectancy (age) provide better performance [20], despite the fact that reference [29] failed to discover the moderating effect of life expectancy on the relationship between IT capacities and organizational performance. Literature

\section{ReviewTheoretical}

\section{Literature Review}

This study was anchored on Technology-Organization-Environment Theory (TOE). TOE theory was founded by [4]; it explains the process through which a company adopts and deploys innovations. TOE identifies three constructs within an organization that comprise of technological, organizational, and environmental contexts. Technological dimension describes both the internal and external technologies relevant to a given firm, this 
comprises current software and hardware in a firm [8]. Organizational construct entails the organization's descriptive features such as the size of scope and structure of management. Environmental dimension refers to the organization's operating environment, including business rivals and legal framework [26]. TOE framework initial presentation has been adapted severally and used widely in IT adoption studies as it provides a useful way in which one can study the adoption and assimilation of different IT innovations in organizations [11].

Reference [26] state that there are elements explained within the TOE model under each of the three constructs. For the technological aspect, they identify relative advantage as referring to the degree to which innovation is perceived to be better than the idea to be superseded. Further, they link compatibility to the extent to which innovation is thought or viewed to be congruent with established values, previous perspectives, and implementation needs. It also encompasses the level to which innovation is perceived to be fairly challenging to learn and use.

For the organizational construct, the authors identify five aspects. Coming first is top management support. This is the top management support of the information system implementation. Secondly, is the organization's readiness in terms of size, cost/financial, and technical resources. They point out that small businesses are most likely to face some form of resource poverty than the much larger firms. In effect, this greatly affects the innovation adoption. Resource poverty manifests also in the form of budget limitations constraints, and ignorance.

Thirdly, are information intensity and product characteristics which refer to the extent of product information details. The fourth aspect to note under organizational construct is the managerial time which refers to the time required to be invested in the planning and adoption of technology. As for environmental construct, reference [26] note the industry pressure element which denotes the high degree of business rivalry and competition which increases the likelihood of innovation adoption for purposes of gaining the much-needed competitive edge in a given industry.

Fifthly, is government pressure or support, which basically points towards the government strategies and initiatives aimed at encouraging small and medium enterprises to adopt new information systems. Lastly, is consumer readiness. Lack of it adversely affects implementation and acts as a detriment to information systems use.

\section{Empirical Literature Review}

A survey by reference [25] found that the characteristics of business organizations such as the innovativeness of the Chief Executive Officer (CEO), information systems knowledge (relative advantage, compatibility, and complexity of IT), and organizational characteristics, including business size and employees' IT knowledge are more likely to adopt IT. Further, the researcher established that CEO's innovativeness was a significant determinant of the decision to adopt IT, but it does not affect the extent of IT adoption. However, the extent of technology adoption is largely determined by organizational characteristics. The study by [26] has been underlined by [16] who established adopter characteristics such as organization size, geographic location, age, management support, CEO's IT skills and experience as key determinants of adoption and IT use. The current study sought to ascertain the extent to which these characteristics impact on ITI and organizational performance

Reference [5] found that internal organizational features such as firm strategy, past experience, and attitudes towards technology and external factors such as infrastructure, business factors, and the competitive environment affect IT adoption and use. The study was based on a sample of 45 SMEs in New England (USA). The study further revealed that organization size, self-efficacy, past technology use, and perceived competitive pressure had a relationship with greater IT adoption and use. 
Reference [13] built up a conceptual model that grouped ICT adoption factors into internal factors that small and medium-sized businesses have control over. The factors identified include lack of time or resources, lack of organizational factors awareness for the CEO, and return on investment. The second category comprised external factors that could not be settled by the business organization. These included a lack of infrastructure, deficient bandwidth, and lack of legislation and regulatory framework. Nevertheless, this model ignored factors such as CEO's innovativeness and employee IT knowledge level. The current study considers these variables.

A study by reference [9] established a significant relationship between CEO's innovativeness and adoption of IT. Knowledge of IT by the CEO is an important element in achieving the full benefits of technological innovation. However, the meta-analysis study found out that the variable had a weak relationship with the adoption of IT. The study sought to examine the moderating effect of CEO's effectiveness on the relationship between the adoption of IT and use. These results were consistent with findings of [25].

\section{Research Methodology}

As recommended by reference [23], this study used explanatory and cross-sectional survey. Reference [23] and [14] believe that the extent and nature of cause-and-effect relationships between variables are determined by explanatory research design. The same authors assert that a cross-sectional survey seeks to evaluate the relationship between variables at a particular time to explain the relationship patterns between variables.

The study target population included ninety-eight public hospitals in Kenya that have integrated managed equipment services, comprising forty-seven level four, forty-seven level five adding up to ninety-four from the forty-seven counties and four national referral hospitals [22].

The study focused on ten departments of the hospitals including Admission, IT, Imaging, Pharmacy, Accident and Emergency, Medical Records, Laboratory, Wards, Surgery, and Hospital Administration. The study used multi-stage sampling to choose the required sample size of 294 respondents. This formed the unit of observations of the study. According to reference [23] and [16], a higher sample is a good population representation, thus minimizing types I and II errors. The researcher developed a semi-structured questionnaire for data collection based on knowledge obtained from a literature review of studies related to ITI and organizational performance [19] and [18]. Using the semi-structured questionnaire, the researcher was able to gather both quantitative and qualitative data from the heads of departments [23]. This study also used secondary data obtained through document review of hospital reports.

\subsection{Empirical Model}

According to reference [27], a moderating variable is a third variable that affects the strength of the link between the independent and dependent variables. Moderation effect testing entails determination of whether the coefficient of the interaction term is statistically significant or assessment of whether it is simply an explanatory variable.

To assess the moderation effect of variable organizational characteristics on the relationship between ITI and public hospital performance. Model (I) which contains organizational characteristics as the moderating variable, was predicted to give the moderator's direction and effect on the independent variables and its overall effect on the dependent variable.

$P P H=\beta 0+\beta 1 I T I+\beta 2 O C+\beta 3 O C * I T I+\varepsilon$ model 1

Where,

ITI - composite index of independent variable ITI and, 
OC - composite index for organization characteristics.

The harmonic mean formula was used to derive the composite index for the variables being studied [7].

$\mathrm{Ci}=\sum \mathrm{fiwi} \div \sum \mathrm{fi}$

Where

$\mathrm{Ci}=$ Variable composite index

$f=$ Respondents sum total

$\mathrm{Wi}=$ component relative weighting

According to reference [27], if the interaction between the predictor variable (ITI) and the variables of the moderator $(O C)$ is not statistically significant $(p>0.05)$, then the variable of organizational characteristics is not a moderator but an explanatory variable. If the interaction is statistically significant, on the other hand, the effect of moderation is supported.

\section{Results and Discussion}

\subsection{Descriptive Results}

The study assessed organizational characteristics to establish whether they moderated the relationship between ITI and performance of public hospitals. The organizational characteristics assessed include the level of the hospitals, the number of employees, and number of ICT innovations initiated by the CEO. The study findings showed that majority of the respondents were from the Level Five hospitals.

On the number of employees, the average hospitals had 259 employees. The hospitals with the highest number of employees had 700; the one with the minimum number of employees had 100. The study further asked respondents to indicate the number of ICT innovations initiated by CEO; averagely, the CEO in the selected public hospitals had initiated two ICT innovations. The CEO, with the highest number of innovations, had ten, while other hospitals had no ICT innovation from their CEOs.

Table 1. Descriptive Results for Organizational Characteristics of Public Hospitals

\begin{tabular}{llllc}
\hline & Minimum & Maximum & Mean & Std. Deviation \\
\hline Level of the hospitals & 4 & 6 & 5.08 & 0.269 \\
$\begin{array}{l}\text { Number of employees } \\
\begin{array}{l}\text { Number of ICT innovations initiated } \\
\text { by the CEO }\end{array}\end{array}$ & 0 & 700 & 259.23 & 171.64 \\
& 100 & 10 & 2.46 & 2.728 \\
\hline
\end{tabular}

Source: Study Data (2018)

\subsection{Test of Hypothesis}

\subsubsection{Test for moderating effect of Organizational Characteristics}

The study further tested whether organization characteristics moderated the relationship between ITI and performance of selected public hospitals in Kenya. The study adopted a moderator regression model, as suggested by [27]. This test involved the computation of composite variable for independent variables (ITI), 
interaction variables computed using product of ITI and Organizational characteristics (moderating variable). Then regression model was fitted with the product of ITI and OC, ITI, organizational characteristics as predictor variables of performance of public hospitals. If the interaction between the independent variable (ITI) and the variables of the moderator $(O C)$ is not statistically significant $(p>0.05)$, then the variable of organizational characteristics is not a moderator but an explanatory variable. On the contrary, the effect of moderation is supported if the interaction is statistically significant.

Table 2. Model Summary for Moderated Regression Analysis

\begin{tabular}{lllll}
\hline Model & $\mathrm{R}$ & R Square & Adjusted R Square & Std. Error of the Estimate \\
\hline 1 & $.797^{\mathrm{a}}$ & .635 & .620 & .64080 \\
\hline
\end{tabular}

a. Predictors: (Constant), ITI*OC, ITI, Organizational Characteristics

Source: Study Data (2018)

The model summary of the moderated regression model shows adjusted $R$-square $=0.620$, which is larger than the adjusted R-square of the model without the organizational characteristics. The findings implied that the inclusion of organizational characteristics enhanced the explanatory power of information technology integration on the performance of public hospitals in Kenya. However, the study used significance level to test whether organization characteristics moderated the relationship between information technology integration and performance of selected public hospitals in Kenya.

Table 3. ANOVA for Moderated Regression Analysis

\begin{tabular}{lllllll}
\hline Model & & Sum of Squares & Df & Mean Square & F & Sig. \\
\hline \multirow{3}{*}{1} & Regression & 53.600 & 3 & 17.867 & 43.511 & $.000^{\mathrm{b}}$ \\
& Residual & 30.797 & 265 & .411 & & \\
& Total & 84.397 & 268 & & & \\
\hline
\end{tabular}

a. Dependent Variable: Performance of Hospitals

b. Predictors: (Constant), ITI*OC, ITI, Organizational Characteristics

Source: Study Data (2018)

To test the goodness of fit of the fitted regression model, the study adopted analysis of variance of the predicted model and actual model. Based on the findings of ANOVA that shows $f=43.511, p=0.000$, the study failed to reject the null hypothesis and concluded that the moderated model had a goodness of fit. The implication of these finding was that the product of ITI and OC, ITI, organizational characteristics significantly predicted the performance of public hospitals in Kenya.

Table 4. Regression Coefficients for Moderated Regression Analysis

\begin{tabular}{lllll}
\hline & B & Std. Error & T & Sig. \\
\hline (Constant) & 0.009 & 0.342 & 0.026 & 0.979 \\
ITI & 1.164 & 0.116 & 9.993 & 0.000 \\
Organizational Characteristics & 1.810 & 0.344 & 5.269 & 0.000 \\
ITI*OC & 1.711 & 0.356 & 4.804 & 0.000 \\
\hline
\end{tabular}

a. Dependent Variable: Performance of Hospitals

Source: Study Data (2018) 
In this study, the requirements for moderation were: if the interaction between the predictor variable and the moderating variable $\left(I T I^{*} O C\right)$ is not statistically significant $(p>0.05)$, then the variable organizational characteristics is not a moderating variable, but an explanatory variable. On the other hand, the effect of moderation is supported if the interaction is statistically significant. Since $\mid T I^{*} O C$ had $p=0.000$, the study rejected the null hypothesis $\mathrm{HO}$ : Organization characteristics do not moderate the relationship between ITI and performance of selected public hospitals in Kenya. Accordingly, it concluded that organizational characteristics significantly moderated the relationship of ITI with the performance of public hospitals in Kenya. The finding implied that Level 5 and national referral hospitals benefit more from ITI compared to Level 4 hospitals. This may be so because such hospitals have many departments and structures that may work better with ITI, unlike small hospitals which can run effectively and efficiently without IT.

These study findings mirror the findings of reference [25]. This author found out that business organizations characteristics such as CEO innovativeness and IS knowledge and organizational characteristics such as business size and employees' IT knowledge were more likely to adopt IT. Reference [16] also established adopter characteristics such as organization size, geographic location, age, management support, CEO IT skills, and experience as key determinants of adoption and use of IT. Similarly, [5] established that internal organizational characteristics such as firm strategy, past experience, and attitudes toward technology and external factors like infrastructure, business-related factors, and the competitive environment affect the adoption and use of IT.

\section{Conclusions and Policy Recommendation}

The study established that organizational characteristics significantly moderated the relationship between information technology integration and the performance of public hospitals in Kenya. Therefore, study concluded that organization characteristics play a major role in an organization's adoption and utilization of ITs. For instance, public hospitals benefit more from information technology integration than smaller hospitals. This may be so because bigger hospitals have many departments and structures that may work better with information technology integration, unlike small hospitals that can work effectively and efficiently without information technology integration.

The study also recommends that public hospitals should align the organizational characteristics of the type of ITs. Otherwise, the technologies should be customized to fit the type of organizational characteristics for better organizational performance.

\section{Acknowledgements}

I acknowledge the overwhelming guidance and support from my supervisors Dr. Stephen M. A. Muathe and Dr. Stephen Waithaka, in the development of this journal. I am equally grateful to Kenyatta University lecturers for their encouragement and support.

\section{References}

1. Belshaw, D. (2005). Development in sub-Saharan Africa: Progress and problems. In Renewing Development in Sub-Saharan Africa (pp. 21-54). Routledge.

2. Cutler, D. (2010). ANALYSIS \& COMMENTARY How Health Care Reform Must Bend The Cost Curve. Health Affairs, 29(6), 1131-1135.

3. Deidda, M., Lupiáñez-Villanueva, F., Codagnone, C. \& Maghiros, I. (2014). Using data envelopment analysis to analyze the efficiency of primary care units. Journal of medical systems, (38:10), 1-10.

4. Depietro, R., Wiarda, E., \& Fleischer, M. (1990). The context for change: Organization, technology, and environment. The processes of technological innovation, 199(0), 151-175. 
5. Dholakia, R. \& Kshetri, N. (2004), Factors affecting the adoption of the internet among SMEs, Small Business Economics, Vol. 23 No. 4, 311-322.

6. Fink, L. (2011). How do IT capabilities create strategic value? Toward greater integration of insights from reductionistic and holistic approaches. European Journal of Information Systems, 20(1), 16-33.

7. Gupta. C. B. (2011). Optimization Techniques in Operation Research. I. K. International Pvt Ltd.

8. Hage, J. (1980). Theories of organizations: Form, process, and transformation (p. 25). New York: Wiley.

9. Hameed, M., \& Counsell, S. (2012). Assessing the influence of environmental and CEO characteristics for adoption of information technology in organizations. Journal of technology management and innovation, $7(1), 64-84$.

10. Harris, J., Mishra, P., \& Koehler, M. (2009). Teachers' Information technology pedagogical content knowledge and learning activity types: Curriculum-based Information technology integration reframed. Journal of Research on Information technology in Education, 41(4), 393-416.

11. Hsu, T. Y., Ke, H. R., \& Yang, W. P. (2006). Knowledge-based mobile learning framework for museums. The Electronic Library, 24(5), 635-648.

12. Jardim-Goncalves, R., Popplewell, K., \& Grilo, A. (2012). Sustainable interoperability: The future of Internetbased industrial enterprises. Computers in Industry, 63(8), 731-738.

13. Kapurubandara, M., \& Lawson, R. (2006). Barriers to Adopting ICT and e-commerce with SMEs in developing countries: An Exploratory study in Sri Lanka. University of Western Sydney, Australia, 82, 20052016.

14. Kothari, C. R. (2009). Research methodology: new age international 2nd edition. London.

15. Merono-Cerdan, A. L. \& Soto-Acosta, P. (2008). External web content and its influence on organizational performance. European Journal of Information Systems, 16(1), 66-80.

16. Muathe, SMA. (2010). The determinants of adoption of information and Communication technology by small and medium Enterprises within the health sector in Nairobi, Kenya. Unpublished Ph.D. Thesis, Kenyatta University.

17. Muiya, B. M. \& Kamau, A. (2013). Universal Health Care in Kenya: Opportunities and challenges for the informal sector workers. Journal of Education and Research, 1(11), 1-10.

18. Mwithiga, L. T., Njihia, J. M., \& Iraki, X. N. (2017). Information Techology (IT) Integration and Firm Performance. International Journal of Economics, Commerce and Management, 5(5), 802-823.

19. Njuguna, J. W. (2013). Strategic social marketing, operating environment, and performance of community-based HIV and Aids organizations in Nairobi County, Kenya. Unpublished Ph.D. Thesis, University of Nairobi, Kenya.

20. Ortega, M. J. R. (2010). Competitive strategies and firm performance: technological capabilities'

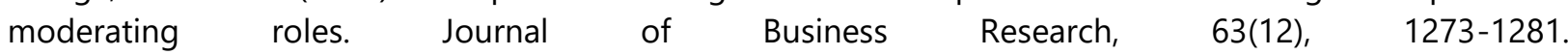
http://dx.doi.org/10.1016/j.jbusres.2009.09.007.

21. Republic of Kenya (2008): Vision 2030 Blueprint. Nairobi: Government Printer.

22. Republic of Kenya (2017). The Health Act 2017. 
23. Saunders, M., Lewis, P., \& Thornhill, A. (2007). Research methods. Business Students 4th edition Pearson Education Limited, England.

24. Shih, A., \& Schoenbaum, S. C. (2007). Measuring hospital performance: The importance of process measures. Commonwealth Fund.

25. Thong, J. Y. (1999). An integrated model of information systems adoption in small businesses. Journal of management information systems, 15(4), 187-214.

26. Tornatzky, L. F., \& Fleisher, M. M., 1990. The Processes of Technological Innovation.

27. Whisman, M. A., \& McClelland, G. H. (2005). Designing, testing, and interpreting interactions and moderator effects in family research. Journal of family psychology, 19(1), 111.

28. WHO (2014). The health of the people: what works: the African Regional Health Health Organization.

Report 2014. World

29. $\mathrm{Wu}$, Z., Huang, Z., \& Wu, B. (2008, September). IT capabilities and firm performance: mediumsizedempirical research from the perspective of organizational decision-making. In 2008 4th IEEE International Conference on Management of Innovation and Technology (pp. 526-531). IEEE. 